\title{
Discussion on Steel Fiber Reinforced Concretes (SFRC)
}

\author{
İrem Şanal* \\ Department of Civil Engineering, Bahcesehir University, Turkey
}

Received: 盋 August 07, 2018; Published: 阱 August 13, 2018

*Corresponding author: İrem Şanal, Department of Civil Engineering, Faculty of Engineering and Natural Sciences, Bahcesehir University, Istanbul, Turkey

\section{Introduction}

The use of Steel Fiber Reinforced Concrete (SFRC) has received a tremendous impulse in the last years in an attempt to push forward the boundaries of high-end structural applications. Generally, concrete is characterized by brittle failure, which limits the application and can be overcome by the inclusion of a small amount of short randomly distributed fibers (steel, glass, synthetic and natural) and can be practiced among others that remedy weaknesses of concrete, such as low ductility, high shrinkage cracking, low durability, etc. SFRC has the ability of excellent tensile strength, flexural strength, impact resistance, fatigue resistance, ductility and crack bridging. Therefore, it has been applied abroad in various professional fields of construction. Steel fiber reinforced concrete (SFRC) is a heterogeneous structural material comprising of typical concrete elements, with the addition of steel fibers to provide tensile resistance. These fibers are discontinuous discrete entities and are distributed and oriented randomly (nominally uniformly) throughout the concrete matrix. SFRC can be used by itself, or in conjunction with conventional reinforcing bars, depending on the application. [1].SFRC's are generally characterized by an enhanced post-cracking tensile residual strength due to the fiber reinforcement mechanisms provided by fibers bridging the crack surfaces [2]. This post peak tensile behavior is influenced mainly by the number of fibers effectively crossing a crack, their angle of orientation, and bonding strength properties of the type of fibers used.

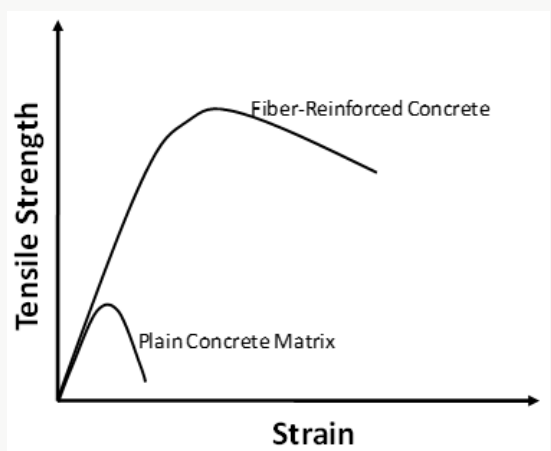

Figure 1: General tensile behavior of concrete.
SFRCs are supposed to enhance the understanding of the material's behaviour and will provide a basis for experimental research into the aspect of scatter in the post-cracking behaviour. It starts with the rheological properties of SFRC, since the workability can strongly influence several stages of the production process [3], and especially the strongest affect is seen on the post-cracking behavior of the composite material. The general tensile behavior of concrete is demonstrated in Figure 1 [4]. Without any fiber reinforcement, the plain concrete matrix exhibits a strain-softening response with low tensile strength and ductility. Because, due to low fracture toughness of concrete, tensile cracks may easily occur when there is an applied stress. The interfacial bond developed between the fibers and matrix makes use of the strength and stiffness of the fibers in reinforcing the brittle matrix. Once the matrix cracks, load can be still transferred across the crack faces through the steel fibers. As the load on the composite is increased, the process of fiber pullout affects load carrying capacity and further contributes to energy dissipation. It has also been known that when using a high volume fraction of fibers with a high specific surface area, the crack bridging potential and the strength of the composite are increased [5,6]. The flexural behavior of SFRC changes substantially compared to plain concrete. Depending on the amount and type of fibers used both the peak load and the ductility can be increased. Explanations will be presented for the fact that the flexural strength can be increased by virtue of fiber addition whereas this is hardly possible with regard to the compressive strength. In bending, the flexural load-bearing capacity can be increased even at low fiber volumes as long as the matrix strength. Fiber reinforced concrete has found interesting new applications in the past two decades due to its inherent superiority over normal plain and reinforced concrete in the following properties: higher flexural strength, better tensile strength and modulus of rupture, higher shear strength, higher shock resistance, better ductility and fatigue resistance, crack resistance and failure toughness [7]. Fiber-reinforced concrete has received its most increasing interest, especially with its presence in conventional concrete, improving certain mechanical properties of concrete. Different fiber types, 
fiber volume fractions and matrix compositions yield very different material behaviors. Even by changing the fiber content alone, the mechanical behavior of the concrete may change from being almost as brittle as plain concrete to even deflection-hardening materials.

In plain concrete, micro cracks develop even before loading, particularly due to drying shrinkage or other causes of volume change. The width of these initial cracks seldom exceeds a few microns. When loaded these micro cracks propagate and open up and due to stress concentration, additional micro cracks are formed. The micro cracks are the main cause for elastic deformation in concrete. Fiber reinforced cement and concrete were developed to overcome these problems. As a result of the incorporation of short discrete fibers cracks propagates into a slow controlled growth. This gives the cement-based materials maximum ductility overcoming its low tensile strength properties. The crack-bridging effect provided by fibers generates residual tensile strengths that improve both the durability and the toughness of concrete. It is the improvement of toughness and the crack distributing properties that motivate the use of fibers. This fact has been contributing to an increasing number of structural applications of SFRC [8]. The beneficial effects of fiber reinforcement are therefore twofold: not only are mechanical properties such as toughness and strength improved, but there are also new possibilities for optimization of materials for certain structures. Nonetheless, there is still a long way to go on the development of methods and design procedures to improve the reliability of this material.

\section{References}

1. B Nemkumar (2001) Fiber Reinforced Cements and Concretes. Canadian Journal of Civil Engineering 28(5): 879-880.

2. P Rossi, G Chanvillard (2000) Fiber Reinforced Concretes. Bagneux, France. RILEM SARL, pp. 810.

3. AG Kooiman (2000) Modelling Steel Fiber Reinforced Concrete for Structural Design, PhD Thesis. Department of Structural and Building Engineering. Delft University of Technology.

4. SP Shah, KG Kuder (2004) Hybrid and High Performance Fiber Reinforced Cementitious Composites, Proceedings of the International Workshop on Advances in Fiber Reinforced Concrete, Bergamo, Italy, p. 83-92.

5. JP Romualdi, GB Batson (1963) Mechanics of Crack Arrest in Concrete, Proceedings of ASCE 89(3): 147-168.

6. B Mobasher, CY Li (1996) Effect of Interfacial Properties on the Crack Propagation in Cementitious Composites, Advanced Cement Based Materials 4(3-4): 93-105.

7. L Ferrara, N Ozyurt, M di Prisco (2010) High Mechanical Performance of Fiber-Reinforced Cementitious Composites: the Role of Casting Flow Induced Fiber Orientation, Materials and Structures, Accepted for publication 44(1): 109-128.

8. M Gunavel, SS Kokila (2015) Experimental Investigation On Behaviour of Hybrid Fiber Reinforced Concrete Beams. Integer J Engg Res.

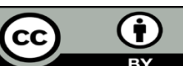

This work is licensed under Creative Commons Attribution 4.0 License

To Submit Your Article Click Here:

Submit Article

DOI: $10.32474 /$ TCEIA.2018.02.000146

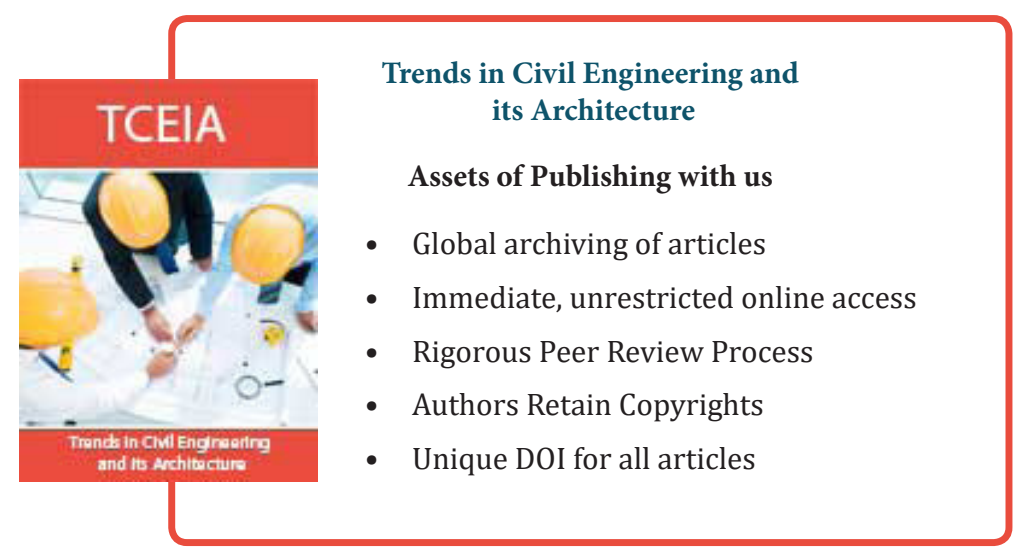

